\title{
Author Correction: Universality of defect-skyrmion interaction profiles
}

\author{
Imara Lima Fernandes ${ }^{1}$, Juba Bouaziz ${ }^{1}$, Stefan Blügel (10 ${ }^{1} \&$ Samir Lounis (iD ${ }^{1}$
}

Correction to: Nature Communications https://doi.org/10.1038/s41467-018-06827-5; published online: 22 October 2018

The original version of this Article contained an error in the Acknowledgements, which incorrectly omitted from the end the following: 'We acknowledge the computing time granted by the JARA-HPC Vergabegremium and VSR commission on the supercomputer JURECA at Forschungszentrum Jülich.' This has been corrected in both the PDF and HTML versions of the Article.

Published online: 15 March 2019

\footnotetext{
(c) (i) Open Access This article is licensed under a Creative Commons Attribution 4.0 International License, which permits use, sharing, adaptation, distribution and reproduction in any medium or format, as long as you give appropriate credit to the original author(s) and the source, provide a link to the Creative Commons license, and indicate if changes were made. The images or other third party material in this article are included in the article's Creative Commons license, unless indicated otherwise in a credit

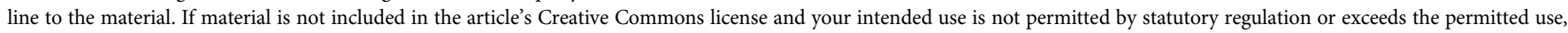
you will need to obtain permission directly from the copyright holder. To view a copy of this license, visit http://creativecommons.org/licenses/by/4.0/.
}

(C) The Author(s) 2019

\footnotetext{
${ }^{1}$ Peter Grünberg Institut and Institute for Advanced Simulation, Forschungszentrum Jülich and JARA, 52425 Jülich, Germany. Correspondence and requests for materials should be addressed to I.L.F. (email: i.lima.fernandes@fz-juelich.de) or to S.L. (email: s.lounis@fz-juelich.de)
} 